\title{
Pulverização foliar com nitrogênio e zinco em milho (Zea mayz L.) "safrinha" em Confresa (MT)
}

Raphael Maia Aveiro Cessa ${ }^{1}$

Luan Sousa de Freitas Lima²

Elmo Pontes de $\mathrm{Melo}^{3}$

\section{Resumo}

Objetivou-se avaliar a produtividade de milho (Zea mayz L.) "safrinha" no município de Confresa (MT) em função da pulverização foliar com nitrogênio e zinco. 0 delineamento experimental utilizado foi o de blocos casualizados dispostos em esquema fatorial 4 × 4 em 4 repetições, totalizando 64 parcelas. Os tratamentos estatísticos foram 4 doses de nitrogênio $(0,00 ; 0,25 ; 0,50 ; 0,75 \mathrm{~kg}$ $\left.\mathrm{ha}^{-1}\right)$ e 4 doses de zinco $\left(0,00 ; 0,40 ; 0,60 ; 0,80 \mathrm{~kg} \mathrm{ha}^{-1}\right)$. As características do milho avaliadas foram matérias frescas e secas das partes aérea (MFPA e MSPA) e raiz (MFR e MFPA), teor foliar de zinco (ZnFOL) e nitrogênio (NFOL), índice de coloração verde foliar (ICV) e produtividade de grãos (PRODU) de milho. Os dados obtidos das características avaliadas foram submetidos à análise de variância (ANAVA) da regressão experimento. Das características com valor de $\mathrm{F}$ da ANAVA significativo a $5 \%$ de probabilidade foram obtidos os modelos de regressão linear múltipla. Foi observado elevação dos valores de ZnFOL e NFOL, o que influenciou a elevação dos valores de ICV. Tais características também influenciaram os valores de MFR e MSR, sendo os maiores observados nos teores de ZnFOL e NFOL dentro das suas faixas de suficiências. Não houve relação direta entre o melhor desenvolvimento da planta de milho e produtividade de grãos com os teores de ZnFOL. O valor de NFOL observado na maior produtividade de grãos de milho corroborou a literatura citada.

Palavras-chave: Tecido vegetal. Sinergia. Doses.

\section{Introdução}

O milho (Zea mays L.) é um dos mais importantes cereais cultivados e consumidos no mundo, não só pelo seu valor econômico, mas pela importância na alimentação humana e animal e por servir como matéria-prima à indústria (MEIRA et al., 2009).

No Brasil a área cultivada com milho "safrinha" em 2014 foi de aproximadamente 8,9 milhões de hectares, com uma produção estimada superior a 46 milhões de toneladas e produtividade relativa de 5.132 kg ha-1 (COMPANHIA NACIONAL DE ABASTECIMENTO - CONAB, 2014). A região Centro-Oeste é a principal produtora do milho safrinha, responsável por $67,1 \%$ da produção nacional, destacando-se, nesse contexto, o Estado de Mato Grosso, responsável por 41,9 \% da produção

1 Instituto Federal de Educação, Ciência e Tecnologia do Mato Grosso - Campus Confresa, professor do Ensino Básico, Técnico e Tecnológico - Área Agronomia. Confresa, Mato Grosso, Brasil. raphael.cessa@cfs.ifmt.edu.br. Avenida Vilma Fernandes, 300, Setor Santa Luzia, Confresa, Mato Grosso, CEP 78652-000.

2 Instituto Federal de Educação, Ciência e Tecnologia do Mato Grosso - Campus Confresa, estudante de graduação - Área Agronomia. Confresa, Mato Grosso, Brasil. Iuanlima.agro@gmail.com. Avenida Vilma Fernandes, 300, Setor Santa Luzia, Confresa, Mato Grosso, CEP $78652-000$.

3 Instituto Federal de Educação, Ciência e Tecnologia do Mato Grosso do Sul - Campus Ponta Porã, professor do Ensino Básico, Técnico e Tecnológico - Área Agronomia. Ponta Porã, Mato Grosso do Sul, Brasil. elmo.melo@ifms.edu.br. Rodovia BR 463, Km 14, s/nº, Ponta Porã, Mato Grosso do Sul, CEP 79909-000. 
nacional. A área cultivada nesse estado foi de 3,5 milhões de hectares, com produtividade média de $5.780 \mathrm{~kg} \mathrm{ha}^{-1}$ na safra 2013/2014 (CONAB, 2014).

O milho é uma das culturas mais exigentes em nutrientes, especialmente o nitrogênio $(N)$, sendo altamente responsivo a esse elemento quanto à produção final (OHLAND et al., 2005). Esse elemento exerce importantes funções no metabolismo vegetal, participar diretamente na biossíntese de proteínas, clorofila (ANDRADE et al., 2003; FLOSS, 2006; FERREIRA et al., 2007), ácidos nucleicos (DNA e RNA) (FERREIRA et al., 2007; FORNASIERI FILHO, 2007), bases nitrogenadas (purinas e purimidas) (TAIZ; ZEIGER, 2009) e fitohormônios (BISSANI et al., 2008).

O N está relacionado diretamente ao crescimento e rendimento da planta, principalmente pelo fato desse nutriente estar associado ao crescimento e desenvolvimento dos drenos reprodutivos e por participar na molécula de clorofila, o que está diretamente associado à atividade fotossintética (MARTIN et al., 2011). Na planta aproximadamente $60 \%$ do N está presente nas folhas, associados aos cloroplastos (BELOW, 2002).

Entre as necessidades nutricionais de micronutrientes na cultura do milho, o zinco ( $\mathrm{Zn}$ ) é de extrema importância (FERREIRA et al., 2001; JAMAMI et al., 2006). O elemento tem atividade efetiva para determinados processos na homeostase fisiológica da planta, pois participa da fotossíntese por meio da enzima carboxilase pirúvica, sendo necessário também para a produção de triptofano, aminoácido precursor do ácido indol acético, hormônio vegetal do crescimento que está envolvido diretamente no metabolismo do $\mathrm{N}$ e é necessário para manutenção da integridade das biomembranas (MALAVOLTA et al., 2006).

Deuner et al. (2008), ao avaliarem experimento em casa de vegetação, observaram respostas significativas nas variáveis estatura de planta e área foliar na cultura do milho, com doses de $\mathrm{N}$ via foliar na forma de ureia. Silva et al. (2009) observaram resultados significantes em algumas variáveis, como diâmetro de colmo, inserção de espiga e estatura de planta, analisadas na cultura do milho, com dose de 0,08 $\mathrm{kg} \mathrm{ha}^{-1}$ de Zn na forma de sulfato de zinco, aplicado via foliar.

Objetivou-se com este trabalho avaliar a produtividade de milho (Zea mayz L.) "safrinha" no município de Confresa (MT) em função da pulverização foliar com nitrogênio e zinco.

\section{Material e métodos}

O trabalho foi realizado no Instituto Federal de Ciências e Tecnologia do Mato Grosso - Campus Confresa (Latitude - 10³8'38" e Longitude - 55³4'08"), altitude de 200 m, em um Argissolo Vermelho-Amarelo Distrófico (EMPRESA BRASILEIRA DE PESQUISA AGROPECUÁRIA - EMBRAPA, 2006), cujos valores da análise química podem ser observados na Tabela 1. A classificação climática de Köppen-Geiger do referido município é definida como Aw (tropical com estação seca), com temperatura média de $19{ }^{\circ} \mathrm{C}$ e temperaturas mínima e máxima, de $19{ }^{\circ} \mathrm{C}$ e $35^{\circ} \mathrm{C}$, respectivamente. A precipitação total anual é superior a $1.800 \mathrm{~mm}$.

Tabela 1. Análises químicas do solo da área experimental. Profundidade amostrada $0-20 \mathrm{~cm}$

\begin{tabular}{|c|c|c|c|c|c|c|c|c|c|c|}
\hline \multicolumn{2}{|c|}{ pH } & Al & $\mathrm{H}+\mathrm{Al}$ & & $\mathrm{Mg}$ & K & $\mathbf{P}$ & $\mathrm{SO}_{2}^{-}$ & $\mathrm{Zn}$ & Mat. org. \\
\hline $\mathrm{H}_{2} \mathrm{O}$ & $\mathrm{CaCl}_{2}$ & & & $\mathrm{cmol}_{\mathrm{c}} \mathrm{C}$ & & & & $\mathrm{mg} d r$ & & \\
\hline 5,6 & 4,8 & 0,14 & 3,60 & 1,11 & 0,48 & 0,13 & 4,8 & - & 1,05 & 16,50 \\
\hline
\end{tabular}

Fonte: Elaborada pelos autores. 
O delineamento experimental utilizado foi o de blocos casualizados dispostos em esquema fatorial $4 \times 4$ em quatro repetições, totalizando 64 parcelas. Os tratamentos estatísticos foram constituídos por 4 doses de nitrogênio $\left(0,00,0,25,0,50\right.$ e 0,75 $\left.\mathrm{kg} \mathrm{ha}^{-1}\right)$ utilizando ureia e 4 doses de zinco $\left(0,00\right.$ 0,40, 0,60 e 0,80 $\left.\mathrm{kg} \mathrm{ha}^{-1}\right)$ utilizando sulfato de zinco. A dimensão da parcela experimental foi de 4,0 m x 4,0 m, sendo sua área útil estabelecida por eliminação de 0,5 m em cada um dos seus lados.

0 milho híbrido simples de ciclo precoce Power Core $^{\mathrm{TM}}$ foi cultivado em 26 de fevereiro de 2015, no espaçamento de 0,45 m entre linhas e 5 plantas por metro, adicionando-se ao solo junto à semeadura $250 \mathrm{~kg} \mathrm{ha}^{-1}$ do formulado 05-17-00. No estádio fenológico V4 foi realizada adubação de cobertura a lanço utilizando $150 \mathrm{~kg} \mathrm{ha}^{-1}$ do formulado 20-00-20.

O fornecimento de zinco e nitrogênio deu-se por meio de pulverização foliar quando a planta de milho encontrava-se no estágio fenológico V8. O pulverizador utilizado foi um costal acionado por $\mathrm{CO}_{2}$, equipado com pontas tipo leque plano na taxa de pulverização de 140 I ha-1.

As características do milho avaliadas foram as matérias frescas e secas das partes aérea (MFPA e MSPA) e raiz (MFR e MFPA), teor foliar de zinco (ZnFOL) e nitrogênio (NFOL) (Embrapa, 1997) em folhas coletadas segundo Malavolta et al. (1997) na pré-florada, índice de coloração verde foliar (ICV), também coletados em pré-florada, além da produtividade de grãos (PRODU) de milho à umidade de $14 \%$.

O ICV foi determinado por meio de um medidor portátil ClorofiLOG1030 ${ }^{\circledR} \mathrm{com}$ intuito de determinação indireta do teor relativo de clorofila total, calculado pela quantidade de luz transmitida pela folha, por meio de dois ou três comprimentos de onda com diferentes absorbâncias, que fornecem uma leitura única proporcional às clorofilas "a" e "b" e aos carotenoides.

Os dados obtidos das características avaliadas foram submetidos à análise de variância (ANAVA) da regressão (GOMES, 1990). Para características com valor de F da ANAVA, significativo a 5 \% de probabilidade, foram obtidos os modelos de regressão linear múltipla com uso do aplicativo computacional Table Curve 3D ${ }^{\circledR} 4.0$.

\section{Resultados e discussão}

Com exceção da MFPA e MSPA da parte aérea, todas as características avaliadas tiveram os valores de $\mathrm{F}$ significativo da análise de variância da regressão para interação doses de zinco $(\mathrm{Zn}) \mathrm{x}$ nitrogênio (N) pelo modelo de regressão múltipla polinomial de segunda ordem (Tabela 2). Ainda as características MFPA e MSPA não foram significativas pelo teste de $\mathrm{F}$ da análise de variância da regressão polinomial de segunda ordem.

Tabela 2. Valores de $\mathrm{F}$ da análise de variância das regressões múltiplas e lineares polinomiais de $2^{\mathrm{a}}$ ordem para matéria fresca da parte aérea (MFPA), matéria seca da parte aérea (MSPA), matéria fresca da raiz (MFR), matéria seca da raiz (MSR), índice de coloração verde (ICV), teor foliar de nitrogênio (NFOL) e zinco (ZnFOL) no milho e produtividade (PROD)

\begin{tabular}{llllllllll}
\hline Fator var. & G.L. & MFPA & MSPA & MFR & MSR & ICV & NFOL & ZnFOL & PROD \\
\hline Múltipla & 5 & $1,40 n s$ & $0,20 n s$ & $4,92^{* *}$ & $4,24^{* *}$ & $3,63^{* *}$ & $4,16^{* *}$ & $48,81^{* *}$ & $9,27^{* *}$ \\
Linear Zn & 2 & $0,41 \mathrm{~ns}$ & $0,07 \mathrm{~ns}$ & - & - & - & - & - & - \\
Linear N & 2 & $0,06 n \mathrm{~ns}$ & $0,86 \mathrm{~ns}$ & - & - & - & - & - & - \\
\hline
\end{tabular}

* $\mathrm{e}^{* *}$ : significativo a 5 e $1 \%$ de probabilidade pelo teste $\mathrm{F}$; ns: não significativo pelo teste $\mathrm{F}$

Fonte: Elaborada pelos autores. 
A pulverização foliar no milho com doses crescentes e conjuntas de Zn e N elevou os valores de ZnFOL e NFOL (Figura 1), "destacando" um sinergismo no processo de absorção desses nutrientes pela planta.

Figura 1. Zinco (ZnFOL) e nitrogênio (NFOL) foliar em milho em função da pulverização foliar com zinco (Zn) e nitrogênio $(N)$
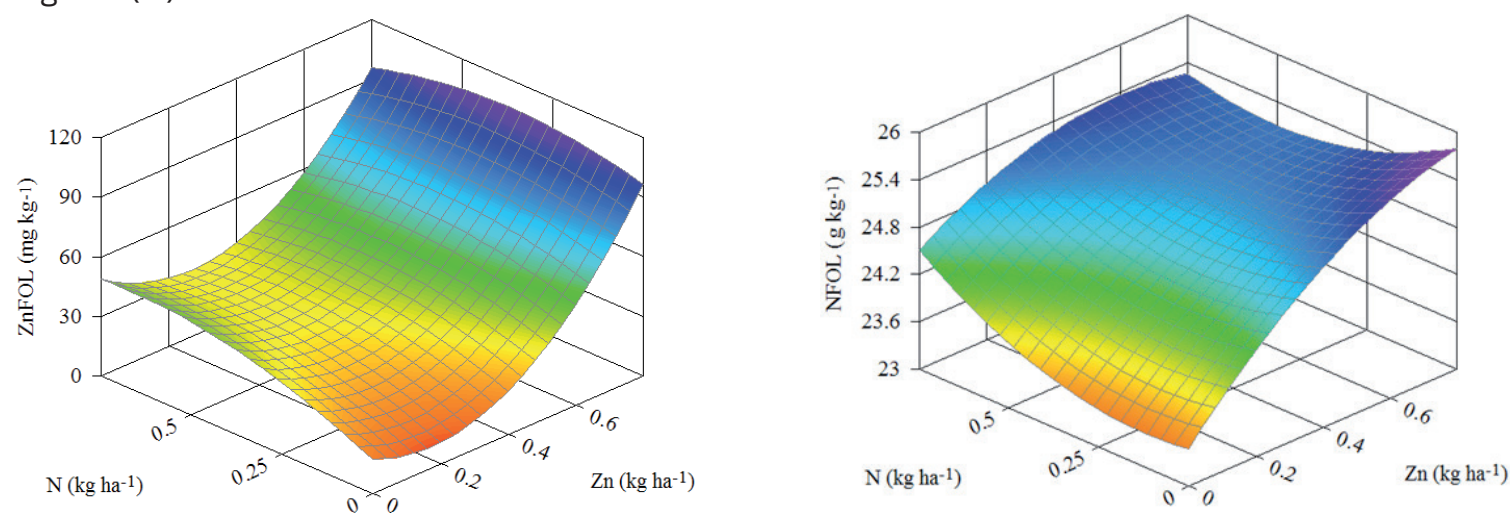

ZnFOL (mg kg-1) $=17,22+(-75,91 \mathrm{Zn})+(93,50 \mathrm{~N})+\left(218,10 \mathrm{Zn}^{2}\right)+\left(-68,70 \mathrm{~N}^{2}\right)+(-53,51 \mathrm{NZn})-\mathrm{R}^{2} 0,90$ NFOL $\left(\mathrm{g} \mathrm{kg}^{-1}\right)=23,47+(4,84 Z n)+(-0,67 \mathrm{~N})+\left(-2,41 \mathrm{Zn}^{2}\right)+\left(2,72 \mathrm{~N}^{2}\right)+(-2,62 \mathrm{NZn})-\mathrm{R}^{2} 0,51$

Fonte: Elaborada pelos autores.

Considerando o sinergismo entre zinco e nitrogênio no processo de suas absorções pela folha do milho, observou-se que o ICV foi crescente com as doses foliares de Zn e N (Figura 2). A cor verde das plantas está diretamente associada com o teor de clorofila foliar, e esse está altamente relacionado com o teor de nitrogênio na maioria das plantas (COELHO et al., 2010), pois o elemento é participante nos grupos pirrol da clorofila, coordenado por um átomo de magnésio (MALHEIROS, 2007). O zinco participa como componente de enzimas desidrogenases, proteinases, peptidases e fosfohidrolases (MARSCHNER, 1995), estando indiretamente relacionado ao mecanismo fotossintético das plantas pertinente à fixação de $\mathrm{CO}_{2}$ pela RUBISCO (BADGER, 2003).

Figura 2. Índice de coloração verde de folhas de milho em função da pulverização foliar com zinco (Zn) e nitrogênio (N)

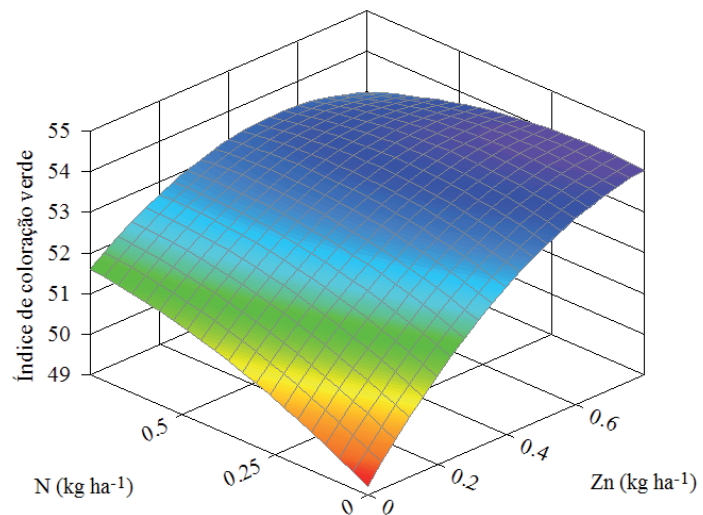

Índice de coloração verde $=49,21+(11,08 Z n)+(5,33 N)+\left(-6,31 Z^{2}\right)+\left(-2,88 N^{2}\right)+(-5,71 Z n N)-R^{2} 0,49$ Fonte: Elaborada pelos autores.

A exposição foliar à radiação solar em folhas contendo mais clorofila favorece o desenvolvimento da planta. Nessas folhas com aparato fotossintético mais eficiente há tendência do acúmulo de carboidratos não estrutural, amido e hexoses (ROMANO, 2005), que de acordo com Gmelig Meyling (1973) é transformado em carboidrato estrutural (celulose e hemicelulose). 
Problemas limitantes à disponibilização de zinco e nitrogênio para as plantas podem interferir negativamente nos teores adequados de clorofila nas folhas responsáveis pela captura da energia solar usada na fotossíntese (TAIZ; ZEIGER, 2009). Bernardes et al. (2014) observaram que o índice relativo de clorofila variou com as doses de nitrogênio aplicadas em cobertura do feijoeiro. Viana e Kiehl (2010) observaram, com adição crescente de nitrogênio ao solo para cultivo de trigo, aumento da concentração da clorofila foliar promovido pela maior concentração de nitrogênio no tecido. Santos (2014) observou que os teores de clorofila "a" e "b" são reduzidos em excesso ou deficiência de zinco foliar, sendo que nessas condições o elemento poderá inibir o transporte de elétrons no fotossistema II (CHALOUB et al. 2005).

A resposta do aumento dos teores de clorofilas nas folhas de plantas com adição de zinco e nitrogênio depende da espécie vegetal, condições edafoclimáticas, tipos de solo, fontes fertilizadoras e épocas de aplicações e doses. Teixeira et al. (2004) observaram que os teores de clorofila não foram influenciados pela adição foliar do zinco em feijoeiro. No trabalho de Netto et al. (2012), o sulfato de amônio propiciou aumento significativo entre outras fontes nitrogenadas no teor de clorofilas em foIhas de milho, sendo as doses testadas desse elemento não suficientes para alterar o teor de clorofila no estágio inicial de desenvolvimento da planta.

Os valores de MFR e MSR elevaram-se com a pulverização foliar no milho de doses crescentes e conjuntas de Zn e N (Figura 3), possivelmente influenciados pelos teores foliares desses elementos, uma vez que interagem e são essenciais aos processos bioquímicos - e fotossintéticos - da fisiologia das plantas (FERREIRA, 1997; SOARES, 2003; SILVA et al., 2008).

Figura 3. Matéria fresca (MFR) e seca (MSR) de raiz de milho em função da pulverização foliar com zinco (Zn) e nitrogênio $(\mathrm{N})$
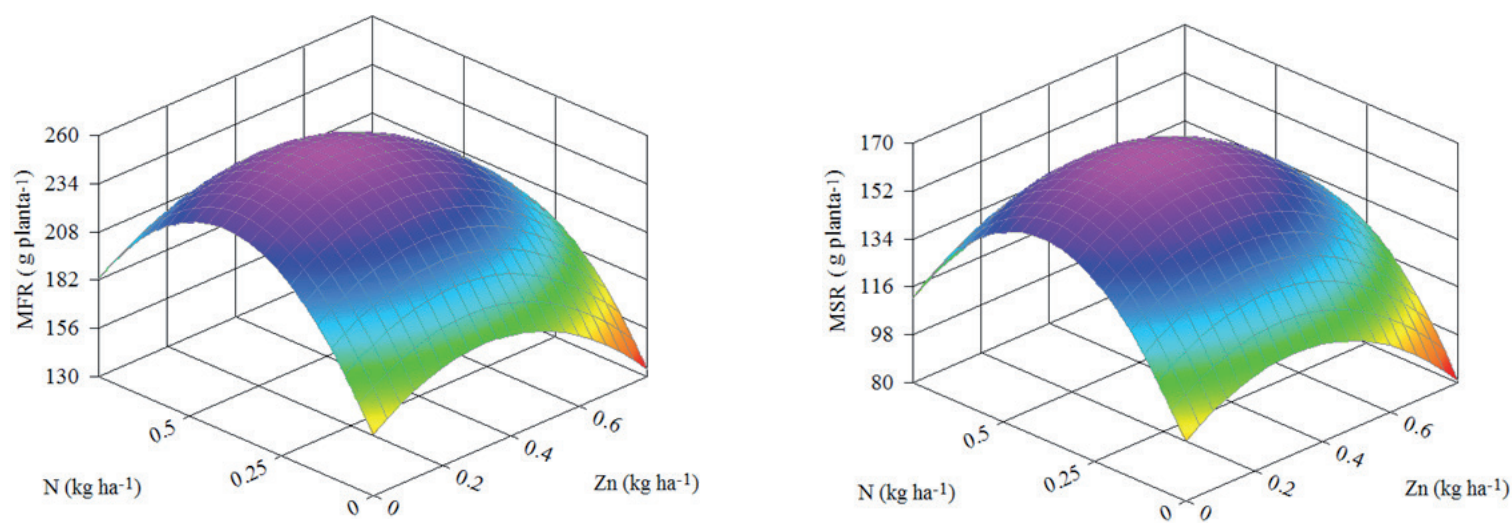

MFR $\left(\right.$ g planta $\left.^{-1}\right)=162,88+(143,32 Z n)+(379,12 N)+\left(-224,23 Z n^{2}\right)+\left(-469,85 N^{2}\right)+(-31,28 N Z n)-R^{2} 0,55$ MSR $\left(\right.$ g planta $\left.^{-1}\right)=102,21+(99,14 Z n)+(270,06 N)+\left(-157,45 Z^{2}\right)+\left(-342,93 N^{2}\right)+(-9,87 N Z n)-R^{2} 0,52$ Fonte: Elaborada pelos autores.

Jamami et al. (2006) observaram que o fornecimento de zinco em doses crescentes às plantas de milho via solo favoreceu a produção de matéria seca da planta. O controle da divisão celular no centro quiescente da raiz vem da copa (ROSOLEM; FRANCO, 2000), pelo transporte de auxina produzida principalmente nas folhas jovens e nas gemas axilares (KERK; FELDMAN, 1994). Ainda, a formação de raízes laterais depende da auxina para a reativação das células quiescentes do periciclo (KERK, 1998). Portanto, o suprimento foliar adequado de zinco em milho tende a promover o melhor crescimento e desenvolvimento radicular da planta pela síntese de auxina.

Viana \& Kiehl e Bernardes et al., citados anteriormente, constataram aumento da concentração da clorofila foliar em função da elevação dos teores de nitrogênio no tecido das espécies vegetais estudadas, havendo maior produção de matéria seca da parte aérea. 
Embora não tenha ocorrido elevação da matéria seca da raiz 40 dias após emergência das plântulas, Rosolem e Franco (2000) constataram translocação de zinco absorvido via foliar às raízes do milho, devendo, no entanto, os teores foliares do referido elemento, que foram de 26 a $36 \mathrm{mg} \mathrm{kg}^{-1}$ de matéria seca, estar dentro da faixa de suficiência que, segundo Chapman (1973), é de 20 a $70 \mathrm{mg} \mathrm{kg}^{-1}$ de matéria seca. No trabalho de Leite et al. (2003), o nível crítico de zinco foliar foi de $34,07 \mathrm{mg} \mathrm{kg}^{-1}$ de matéria seca, 45 dias após emergência das plântulas, havendo maior produção de matéria seca da parte aérea. Nos trabalhos de Garlão (1995) e Souza et al. (1995), esses valores foram respectivamente $16 \mathrm{mg} \mathrm{kg}^{-1} \mathrm{e}$ $20 \mathrm{mg} \mathrm{kg}^{-1}$ para condições de estágio fenológico semelhante das plantas de milho, sugerindo que a planta não responde adequadamente, em termos de desenvolvimento, a valores mais elevados de zinco foliar.

No trabalho de Hurtado et al. (2010), o teor foliar de nitrogênio em que se observaram os maiores valores de matéria seca da parte aérea foram entre 11 e $16 \mathrm{~g} \mathrm{~kg}^{-1}$ de matéria seca, sendo $31,3 \mathrm{~g} \mathrm{~kg}^{-1}$ o valor observado para máxima produtividade de grãos de milho. Gott et al. (2014) constataram no estágio fenológico R1 para nitrogênio a faixa de suficiência entre 26,50 e 44,10 g kg-1 de matéria seca das folhas do milho, correlacionando com as maiores produtividades de grãos.

No presente trabalho, foi para os valores de ZnFOL e NFOL próximos a $20 \mathrm{mg} \mathrm{kg}^{-1}$ e $30 \mathrm{~g} \mathrm{~kg}^{-1}$ de matéria seca, respectivamente, valores próximos aos limites mínimos das suas referidas faixas de suficiências, que observaram-se maiores valores de MFR e MSR, bem como do ICV. No entanto, o maior valor de produtividade de grãos de milho (Figura 4) foi observado para os valores de ZnFOL e NFOL próximos a $90 \mathrm{mg} \mathrm{kg}^{-1}$ e $26 \mathrm{~g} \mathrm{~kg}^{-1}$ de matéria seca respectivamente.

Figura 4. Produtividade de milho em função da pulverização foliar com zinco (Zn) e nitrogênio (N)

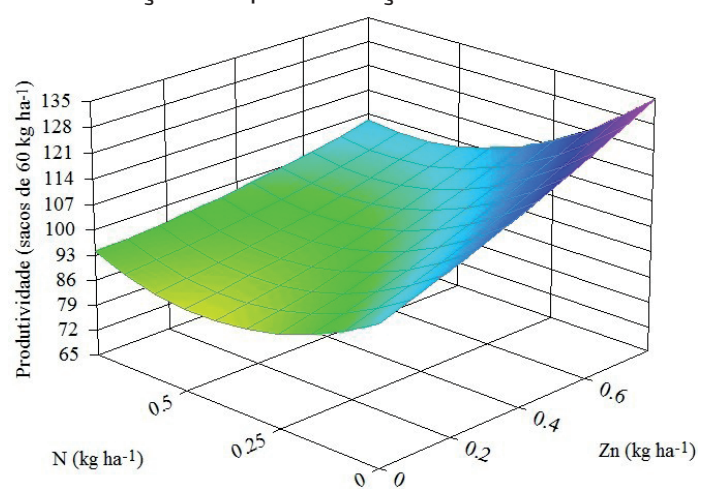

Produtividade $\left(\operatorname{sacos} 60 \mathrm{~kg} \mathrm{ha}^{-1}\right)=102,895+(30,41964 \mathrm{Zn})+(-68,6928 \mathrm{~N})+\left(11,58239 \mathrm{Zn}^{2}\right)+\left(75,74 \mathrm{~N}^{2}\right)+(-$ $34,4626 N Z n)-R^{2} 0,62$

Fonte: Elaborada pelos autores.

Considerando as informação descritas, não houve relação direta entre o melhor desenvolvimento da planta de milho - comprovado por maiores valores das suas características de crescimento - e a produtividade de grãos com os teores de ZnFOL, sendo menor o valor de tal característica para o melhor desenvolvimento da planta em comparação àquele observado para a maior produtividade de grãos de milho. 0 valor de NFOL próximo a $26 \mathrm{~g} \mathrm{~kg}^{-1}$ de matéria seca corroborou a literatura citada quanto à obtenção de maiores produtividades de grãos de milho.

\section{Conclusões}

Houve aumento dos valores de ZnFOL e NFOL com a pulverização foliar em doses crescentes e conjuntas de Zn e N no milho, o que influenciou a elevação dos valores de ICV. Tais características também influenciaram os valores de MFR e MSR, sendo os maiores observados nos teores de ZnFOL e NFOL dentro das suas faixas de suficiências. 


\title{
Leaf spraying with nitrogen and zinc in maize (Zea mayz L.) "safrinha" in Confresa (MT)
}

\begin{abstract}
The objective of this study was to evaluate the yield of maize (Zea mayz L.) "safrinha" in the municipality of Confresa (MT) as a function of leaf spraying with nitrogen and zinc. The experimental design adopted was the randomized blocks arranged in a $4 \times 4$ factorial scheme in 4 replications, totaling 64 plots. Statistical treatments were 4 doses of nitrogen $(0.00,0.25,0.50,0.75 \mathrm{~kg}$ ha- 1$)$ and 4 doses of zinc $(0.00,0.40,0.60,0.80 \mathrm{Kg}$ ha- 1$)$. The characteristics of the evaluated corn were fresh and dry matter of the aerial parts (MFPA and MSPA) and root (MFR and MFPA), foliar zinc content (ZnFOL) and nitrogen (NFOL), leaf green color index (ICV) Corn (PRODU). The data obtained from the evaluated characteristics were submitted to analysis of variance (ANAVA) of the regression experiment. The multiple linear regression models were obtained from the characteristics with $F$ value of the significant ANAVA at $5 \%$ probability. Elevation of ZnFOL and NFOL values was observed, which influenced the elevation of ICV values. These characteristics also influenced the values of MFR and MSR, the largest values observed were in the levels of ZnFOL and NFOL within their ranges of sufficiencies. There was no direct relationship between the better development of the corn plant and grain yield with the ZnFOL contents. The value of NFOL observed in the highest productivity of corn grains corroborated the mentioned literature.
\end{abstract} Keywords: Plant tissue. Synergy. Doses.

\section{Referências}

ANDRADE, A. C.; FONSECA, D. M.; QUEIROZ, D. S. SALGADO, L. T.; CECON, P. R. Adubação nitrogenada e potássica em capim elefante (Pennisetum purpureum Schum. cv. Napier). Revista Ciência e Agrotecnologia, Ed. Especial, p. 1643-1651, 2003.

BELOW, F. E. Fisiologia, nutrição e adubação nitrogenada do milho. (Informações Agronômicas, 99). p. 7-12 Piracicaba: POTAFOS, 2002.

BERNARDES, T. G.; SILVEIRA, P. M. da.; MESQUITA, M. A. M.; CUNHA, P. C. R. da. Resposta do feijoeiro de outono-inverno a fontes e doses de nitrogênio em cobertura. Bioscience Journal, v. 30, n. 2, p. 458-468, 2014.

BISSINI, C. A.; GIANELO, C.; CAMARGO, F. A. O.; TEDESCO, M. J. Nitrogênio e adubos nitrogenados. In: BISSINI, C. A.; GIANELO, C.; CAMARGO, F. A. O.; TEDESCO, M. J. (Ed.) Fertilidade dos solos e manejo da adubação de culturas. 2. ed. p. 145-168, Poto Alegre: Metrópole, 2008.

CHALOUB, R. M.; MAGALHÃES, C. C. P.; SANTOS, C. P. dos. Early toxic effects of zinc on PSII of Synechocystis aquatilis f. aquatilis (cyanophyceae). Journal Phycology, v. 41, n. 6, p. 1162-1168, 2005.

CHAPMAN, H. D. Diagnostic criteria for plants and soils. Riverside, Chapman, 1973. 793p.

COELHO, F. S.; FONTES, P. C. R.; PUIATTI, M.; NEVES, J. C. L.; SILVA, C. de CASTRO. Dose de nitrogênio associada à produtividade de batata e índices do estado de nitrogênio na folha. Revista Brasileira de Ciência do Solo, v. 34, n. 4, p. 1175-1183, 2010. 
COMPANHIA NACIONAL DE ABASTECIMENTO (CONAB). Acompanhamento da safra brasileira grãos: safra 2014/2015. Brasília, v. 2, n. 1 - Primeiro Levantamento, Brasilia, p. 1-89, out. 2014.

DEUNER, S.; NASCIMENTO, R. do; FERREIRA, L. S.; BADINELLI, P. G.; KERBER, R. S. Adubação foliar e via solo de nitrogênio em plantas de milho em fase inicial de desenvolvimento. Ciência e Agrotecnologia, v. 32, n. 5, p. 1359-1365, 2008.

EMPRESA BRASILEIRA DE PESQUISA AGROPECUÁRIA (EMBRAPA). Sistema brasileiro de classificação de solos. Rio de Janeiro: Centro Nacional de Pesquisa de Solos, 2006. 306p.

FERREIRA, A. C. B. Efeitos da adubação com N, Mo e Zn sobre a produção, qualidade de grãos e concentração de nutrientes no milho. 1997. 73f. Dissertação (Mestrado) - Universidade Federal de Viçosa, Viçosa, 1997.

FERreirA, A. C. B.; ARAUjO, G. A. A.; PEREIRA, P. R. G.; CARDOSO, A. A. Características agronômicas e nutricionais do milho adubação com nitrogênio, molibdênio, e zinco. Scientia Agrícola, $v$. 58, n. 1, p. 131-138, 2001.

FERREIRA, L. A.; OLIVEIRA, J. A.; PINHO, E. V. R. V.; QUEIROZ, D. L. Bioestimulantes e fertilizantes associados ao tratamento de sementes de milho. Revista Brasileira de Sementes, Brasília, v. 29, n. 2, p. 80-89, 2007.

FLOSS, E. L. Fisiologia das plantas cultivadas: o estudo que está por trás do que se vê. Passo Fundo: Universidade de Passo Fundo. p. 751, 2006.

FORNASIERI FILHO, D. Manual da cultura do milho. Jaboticabal: Funep, 2007.

GARLÃO, E. Z. Níveis críticos de zinco para milho cultivado em Latossolo Vermelho-Amarelo, fase Cerrado. Revista Brasileira de Ciência do Solo, v. 19, n. 2, p. 255-260, 1995.

GMELIG MEYLING, H. D. Effect of light intensity, temperature and daylength on the rate of leaf appearance of maize. Netherlands Journal of Agricultural Science, v. 21, n. 1, p. 68-76, 1973.

GOMES, F. P. Curso de estatística experimental. 13. ed. Piracicaba: Nobel, 1990. 468p.

GOTT, R. M.; AQUINO, L. A. de.; CARVAlHO, A. M. X. de.; SANTOS, L. P. D. dos.; NUNES, P. H. M. P.; COELHO, B. S. Índices diagnósticos para interpretação de análise foliar do milho. Revista Brasileira de Engenharia Agrícola e Ambiental, v. 18, n. 11, p. 1110-1115, 2014.

HURTADO, S. M. C.; SILVA, C. A.; RESSENDE, A. V. DE.; CORAZZA, E. J.; SHIRATSUCHI, L. S.; HIGASHIKAWA, F. S. Sensibilidade do clorofilômetro para diagnóstico nutricional de nitrogênio no milho. Ciência Agrotecnológica, v. 34, n. 3, p. 688-697, 2010.

JAMAMI, N.; BÜLL, L. T.; CORRÊA, J. C.; RODRIGUES, J. D. Resposta da cultura do milho (Zea mays L.) à aplicação de boro e de zinco no solo, Acta Scientiarum. Agronomy, Maringá, v. 28, n. 1, p. 99-105, 2006.

KERK, N. The root meristem and its relationship to root system architecture. In: BOX, J. E. (ED). Root demographics and their efficiencies in sustainable agriculture, grasslands and forest ecosystems. Dordrecht, Kluwer Academic Publishers, 1998. p. 509-521. 
KERK, N.; FELDMAN, L. The quiescent centre in roots of maize: initiation, maintenance and role in organization of the root apical meristem. Protoplasma, v. 83, p. 100-106, 1994.

LEITE, U. T.; AQUINO, B. F. de.; ROCHA, N. R. C.; SILVA, J. da. Níveis críticos foliares de boro, cobre, manganês e zinco em milho. Bioscience Journal, v. 19, n. 2, p. 115-125, 2003.

MALAVOLTA, E. Elementos de nutrição de plantas. São Paulo: Agronômica Ceres, 2006.

MALHEIROS, G. C. Estudo da alteração da cor e degradação da clorofila durante armazenagem de erva-mate tipo chimarrão. 2007. 103f. Dissertação (Mestrado) - Universidade Federal de Santa Maria, Santa Maria, 2007.

MARSCHNER, H. Mineral nutrition of higher plants. 2. ed. San Diego: Academic Press, 1995.

MARTIN, T. N.; PAVINATO, P. S.; SILVA, M. R.; ORTIZ, S.; BERTONCELI. Fluxo de nutrientes em ecossistemas de produção de forragens conservadas. In: SIMPÓSIO SOBRE PRODUÇÃO E UTILIZAÇÃO DE FORRAGENS CONSERVADAS, 4., Maringá (PR), 28 e 29 de abril de 2011. Anais... Maringá, 2011, p.173-219.

MEIRA, F. A.; BUZETTI, S.; ANDREOTTI, M.; ARF, O.; SÁ, M. E.; ANDRADE, J. A. C. Fontes e épocas de aplicação do nitrogênio na cultura do milho irrigado. Semina: Ciências Agrárias, v. 30, n. 2 p. 275-284, 2009.

NETTO, A. P. C.; FREITAS, R. F. de.; PALHARINI, C.; RIVA, L. C.; SANTOS, T. T. M. dos.; LEITE, F. F. S.; OLIVEIRA, L. J. de.; RAGAGNIN, V. A.; GILEFI, F. S. Efeito de Diferentes Fontes de Nitrogênio no Teor de Clorofila em Diferentes Híbridos de Milho Cultivados em Segunda Safra. In: CONGRESSO NACIONAL DE MILHO E SORGO, 29., Águas de Lindóia - 26 a 30 de agosto de 2012. Anais... Águas de Lindóia, 2012. p.204 - 210.

OHLAND, R. A. A.; SOUZA, L. C. F.; HERMANI, L. C.; MACHETTI, M. E.; GONÇALVES, M. C. Cultura de coberturas do solo e adubação nitrogenada no milho em plantio direto. Ciência e Agrotecnologia, v. 29 , n. 3, p. 538-544, 2005.

ROMANO, M. R. Desempenho fisiológico da cultura de milho com plantas de arquitetura contrastante: parâmetros para modelos de crescimento. 2005. 100f. Tese (Doutorado) - Escola Superior de Agricultura "Luiz de Queiroz", Piracicaba, 2005.

ROSOLEM, C. A.; FRANCO, G. R. Translocação de zinco e crescimento radicular em milho. Revista Brasileira de Ciência do Solo, v. 24 n. 4, p. 807-814, 2000.

SANTOS, J. O. dos. Deficiência e excesso de zinco em cafeeiro: metabolismo de carboidratos e antioxidantes. Lavras, 2014. 68f. Dissertação (Mestrado) - Universidade Federal de Lavras, 2014.

SILVA, T. R. B. da.; GUZELLA, R. E.; FREITAS, L. B. de.; MAIA, S. C. M. Efeito da aplicação de nitrogênio em cobertura e zinco via foliar no milho safrinha em semeadura direta. Agrarian, v. 2, n. 3, p. 29-39, 2009.

SILVA, T. T. A.; PINHO, E. V. R. V.; CARDOSO, D. L.; FERREIRA, C. A.; ALVIM, P. O. ; COSTA, A. A. F. da. Qualidade fisiológica de sementes de milho na presença de bioestimulantes. Ciência Agrotecnológica, v. 32, n. 3, p. 840-844, 2008. 
SOARES, M. A. Influência de nitrogênio, zinco e boro e de suas respectivas interações no desempenho da cultura de milho (Zea mays L.). Piracicaba, 2003. 92f. Dissertação (Mestrado) - Escola Superior de Agricultura "Luiz de Queiroz", 2003.

SOUZA, E. C. A.; SANTIAGO, G.; OLIVEIRA, L. C. L.; COUTINHO, E. L. M.; LIMA, L. A. Resposta do milho à adubação com fósforo e zinco. Acta Scientiarum, v. 13, n. 1, p. 39-49, 1995.

TAIZ, L.; ZEIGER, E. Fisiologia vegetal. 4. ed. Porto Alegre, Artmed, 2009. 848p.

TEIXEIRA, R. T.; BORÉM, A.; ANDRADE, M. J. B. de.; GIÚDICE, M. P. D.; CECON, P. R. Teores de clorofila em plantas de feijoeiros influenciadas pela adubação com manganês e zinco. Acta Scientiarum Agronomy, v. 26, n. 2, p. 147-152, 2004.

VIANA, E. M.; KIEHL, J. C. Doses de nitrogênio e potássio no crescimento do trigo. Bragantia, v. 69, n. 4, p. 975-982, 2010.

\section{Histórico editorial:}

Submetido em: 14/07/2015

Aceito em: 02/03/2016

Como citar:

ABNT

CESSA, R. M. A.; LIMA, L. S. F.; MELO, E. P. de. Pulverização foliar com nitrogênio e zinco em milho (Zea mayz L.) "safrinha" em Confresa (MT). Revista Agrogeoambiental, Pouso Alegre, v. 9, n. 1, p.55-64, jan./mar. 2017.

DOI: http://dx.doi.org/10.18406/2316-1817v9n12017869

$\underline{A P A}$

CESSA, R. M. A., LIMA, L. S. F. \& MELO, E. P. de. (2017). Pulverização foliar com nitrogênio e zinco em milho (Zea mayz L.) "safrinha" em Confresa (MT). Revista Agrogeoambiental, 9 (1), 55-64. DOI: http://dx.doi.org/10.18406/2316-1817v9n12017869

ISO

CESSA, R. M. A.; LIMA, L. S. F. e MELO, E. P. de. Pulverização foliar com nitrogênio e zinco em milho (Zea mayz L.) "safrinha" em Confresa (MT). Revista Agrogeoambiental. 2017, vol. 9, n. 1, pp. 55-64. elSSN 2316-1817. DOI: http://dx.doi.org/10.18406/2316-1817v9n12017869

VANCOUVER

Cessa RMA, Lima LSF, Melo EP. Pulverização foliar com nitrogênio e zinco em milho (Zea mayz L.) "safrinha" em Confresa (MT). Rev agrogeoambiental. 2017 jan/mar; 9(1): 55-64. DOI: http://dx.doi.org/10.18406/2316-1817v9n12017869 